\title{
The location of InsP3 receptors in Purkinje cells of murine cerebellum does not supports a direct interaction in the transfer of calcium ions between ER and mitochondria
}

\author{
Ramesh Iyer (1), Clara Franzini-Armstrong (2) \\ (1)Division of Cardiology, Children Hospital of Philadelphia, Philadelphia, PA, USA; (2) \\ Department of Cell and Developmental Biology, School of Medicine, University of Pennsylvania, \\ Philadelphia, PA, USA \\ This article is distributed under the terms of the Creative Commons Attribution Noncommercial License (CC BY-NC 4.0) which permits \\ any noncommercial use, distribution, and reproduction in any medium, provided the original author(s) and source are credited.
}

\begin{abstract}
The inositol-3-phosphate receptors (IP3Rs) of cerebellar Purkinje cells are located in abundant, large stacks of endoplasmic reticulum (ER) cisternae. Using thin section electron microscopy, we identify very frequent associations of the ER stacks with mitochondria. The associations have two components: a single, close ER-mitochondria contact on one side to the stack, and multiple layers of ER cisternae decorated by IP3Rs receptors on the side away from the mitochondria. Due to their location in the stacks, IP3Rs are never in contact with the mitochondria, although they are in their vicinity. We conclude that transfer of Ca2+ between ER and mitochondria is not directly mediated by IP3Rs, but is based on mitochondrial $\mathrm{Ca} 2+$ uptake from the local cytoplasmic spikes during IP3Rs' activity.
\end{abstract}

Key Words: IP3 receptors; mitochondria; cerebellum Purkinje cells.

Eur J Transl Myol 31 (3): 9935, 2021 doi: 10.4081/ejtm.2021.9935

$\mathbf{C a}^{2+}$ are universal intracellular messengers by virtue of the fact that the ions are segregated within membranelimited compartments, mostly endo- and sarcoplasmic reticulum, (ER and SR), ${ }^{1}$ and are maintained at extremely low levels in the cytoplasm. $\mathrm{Ca}^{2+}$ is released on demand into the cytoplasm through multiple isoforms of high conductance channels that are part of two analogous families: the inositol 1,4,5-trisphosphate receptors $\left(\mathrm{IP}_{3} \mathrm{R}\right),{ }^{2-5}$ and the ryanodine receptors (RyRs). ${ }^{6}$ IP3Rs and RyRs are intrinsic components of ER and SR membranes, including the cytoplasmic layer of the nuclear envelope. Both RyRs and IP3Rs are present in the majority of cells, but at different levels. For example, skeletal muscle is rich in RyRs and relative poor in IP3Rs, cardiac muscle, is also rich in RyRs, but has a slightly higher level of IP3Rs and most neurons are very rich in IP3Rs and fairly poor in RyRs.

Mitochondrial respiration is activated by a low concentration of $\mathrm{Ca}^{2+}$ in the matrix. ${ }^{7}$ It is well established that mitochondria take up a small amount of $\mathrm{Ca}^{2+}$ following its release from ER and SR and that this uptake is very fast after a release. ${ }^{8,9}$ Uptake occurs during the relative short events of E-C coupling and contraction in skeletal and cardiac muscles. ${ }^{10}$ Thus mitochondria are involved to some extent in the cell $\mathrm{Ca}^{2+}$ homeostasis, most significantly in cells rich of the organelles. ${ }^{11}$
The functional relationship between ER/SR (the $\mathrm{Ca}^{2+}$ sources), the clusters of RyR and IP3Rs release sites (the release valves) and mitochondria (the $\mathrm{Ca}^{2+}$ sinks) is facilitated by the close proximity between the organelles and their connection by tethers, most obvious in liver cells, ${ }^{12-14}$ and striated muscles, ${ }^{15,16}$ leading to the concept of a mitochondria associated membrane (MAM) system. ${ }^{17}$ Although direct molecular exchanges between ER/SR and mitochondrion membranes are demonstrated, this may not involve a direct transfer of $\mathrm{Ca}^{2+}$ mediated by the two types of release channels. Indeed, the RyR $\mathrm{Ca}^{2+}$ release sites in skeletal and cardiac muscles are located in proximity of mitochondria but there is no direct contact between RyRs and the mitochondrion membrane $^{15,18}$ In the case of IPR3s, the structural evidence is lacking. Due to the relative scarcity of IP3R, 1 - the exact position of the channels in MAMs in relation to the mitochondrion membrane has not been established by ultrastructure, and a close contact between the channels and the outer mitochondrial has been assumed, but not demonstrated.

Prominent and frequent arrays of ER stacks of Purkinje cells of the cerebellum are a rich source of IP3R3s. ${ }^{1,2,4}$ The electron dense particles between the ER membranes of stacks have been clearly identified as IP3Rs on the basis of immunolabeling and ultrastructure. ${ }^{19}$ The 


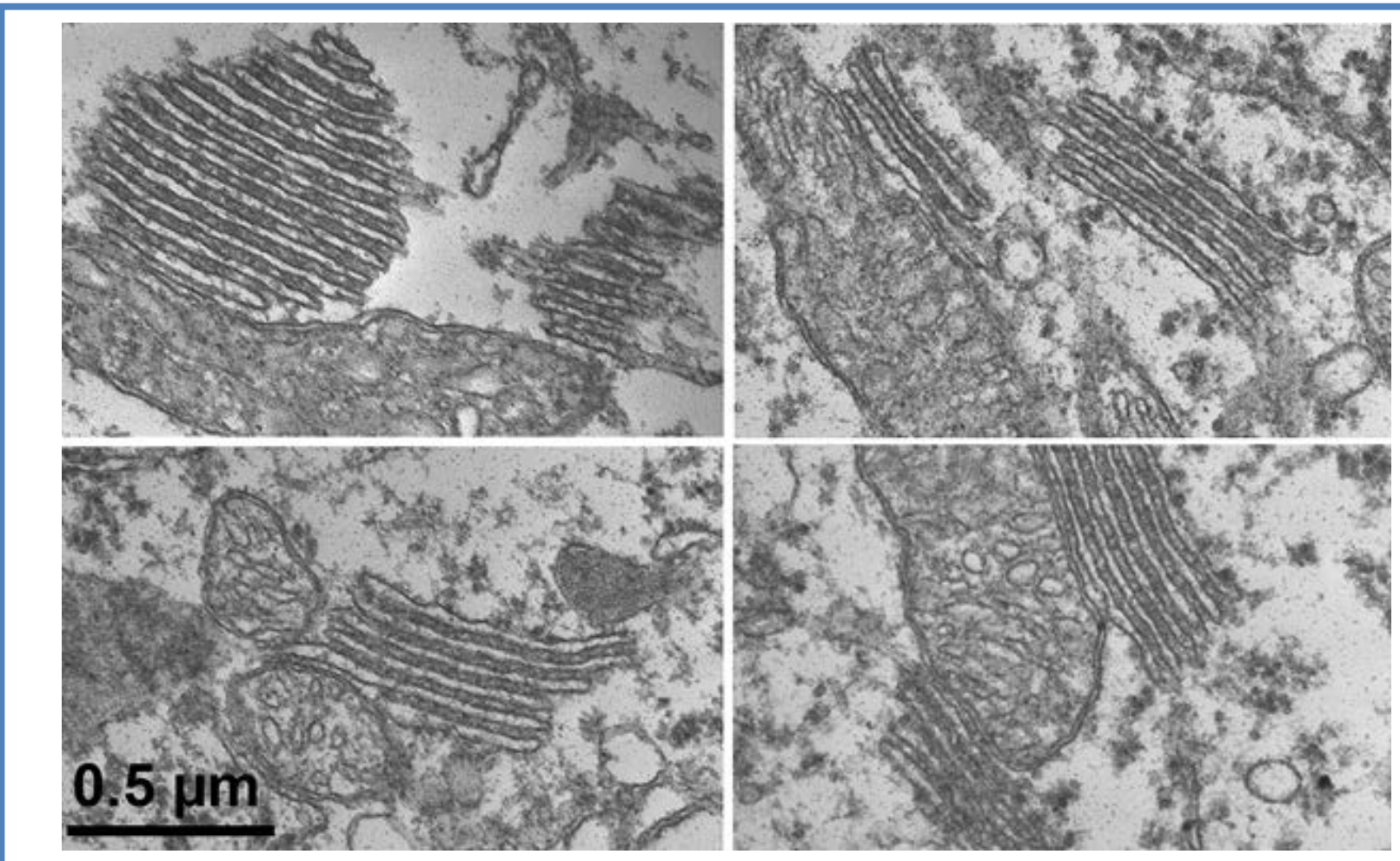

Fig 1. Selection of images from the soma of a rat cerebellar Purkinje cell showing a variety of associations between ER membranes stacks and mitochondria. One to two stacks are closely apposed to the mitochondria and in all cases the distances between the membranes of mitochondrion and of the stack facing it are narrow.

Figure 1 A and D are shown at higher magnification in Figures 3 and 2 respectively.

molecules are arranged in the ER with the cytoplasmic domains extending on the cytoplasmic side of the membranes and are natively organized in semicrystalline arrays with parameters very similar to those of RyRs, despite the difference in size of the two channels (compare Katayama E, et al. $1996 .{ }^{19}$ with Paolini C, et al.

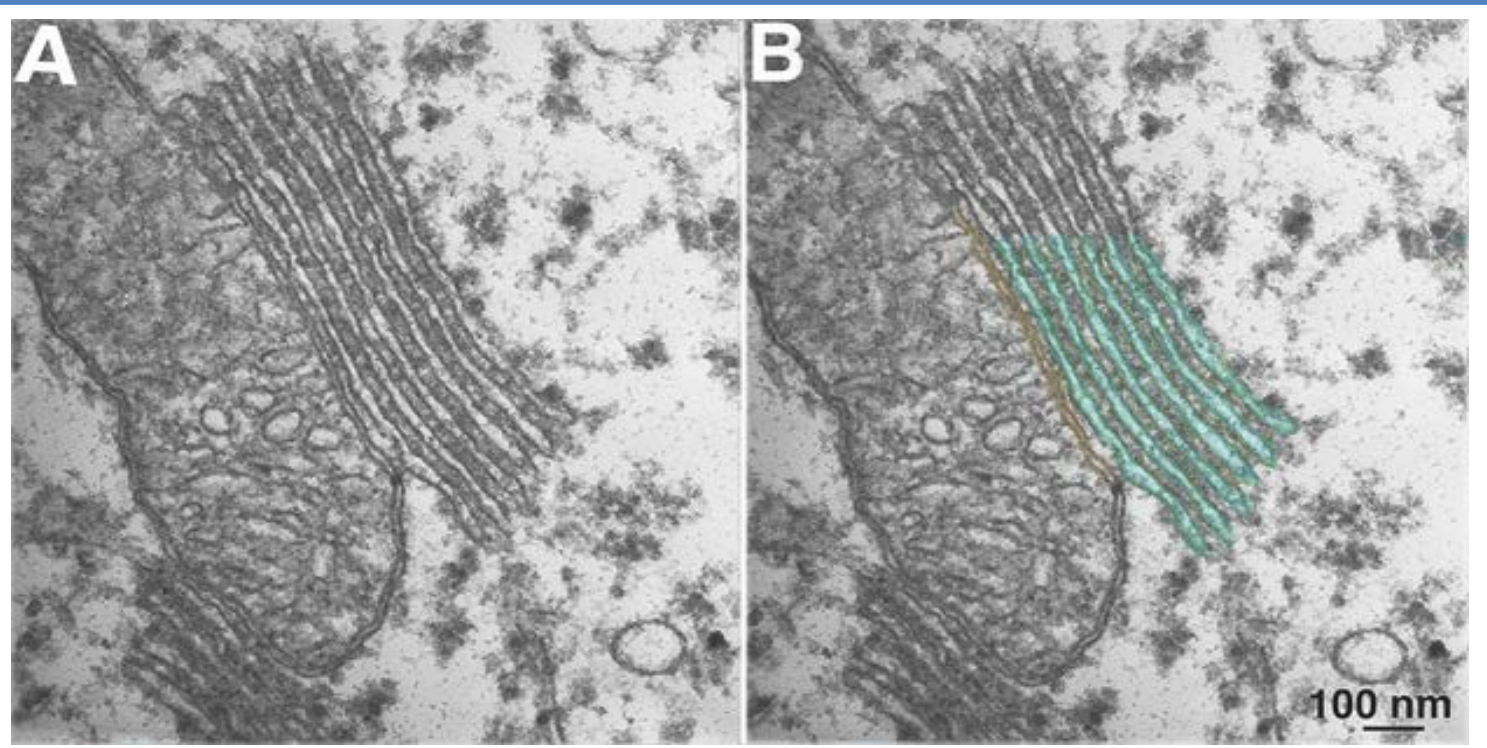

Fig 2. A) Two associations between ER stacks and a mitochondrion, a brief and a prologued one. B) In the same image, some of the stack membranes and the lumen of the ER cisternae are colored in green The inner and the outer mitochondrial membranes are in orange. The green-to-orange space is narrow, while the space between facing stack cisternae is wider and occupied by small densities. 
Transfer of calcium ions between ER and mitochondria in Purkinje cells

Eur J Transl Myol 31 (3): 9935, 2021 doi: 10.4081/ejtm.2021.9935

2004) ${ }^{20}$ Release of caged Ins3P in cultured Purkinje cells results in a robust release of $\mathrm{Ca}^{2+}$ into the cytoplasm of both dendrites and soma. ${ }^{21}$ The abundance and clustering of Ip3Rs in these cells offers a unique opportunity for exploring the spatial relationship between IP3Rs and the mitochondrial membrane.

\section{Materials and Methods}

A single adult rat was euthanized by $\mathrm{CO}_{2}$ anesthesia. The brain was fixed by perfusion through the carotid artery with $6 \%$ glutaraldehyde in $0.1 \mathrm{M}$ cacodylate buffer $\mathrm{pH}$ 7.2. After removing from the skull, small sections of the cerebellum were post fixed for $1 \mathrm{hr}$ in $2 \% \mathrm{OsO}_{4}$ in the same buffer, stained en-bloc with saturated uranyl acetate for 3 hrs, dehydrated and embedded in Epon. Thin sections were imaged after staining with uranyl acetate and lead solution, as detailed in Lavorato M, FranziniArmstrong C. (2017). ${ }^{22}$
Figures.1 and 2 were previously published in FranziniArmstrong, C. "MUSCLE. Fifty years of images". published in QEIOS Journal, April 2021. The journal does not hold copyright.

\section{Results}

The murine Purkinje cell soma is occupied by a high density of randomly distributed mitochondria, ER stacks, and mitochondria-associated stacks (Figure 1). While the ER stacks and their ultrastructure have been illustrated in great detail and their content of IP3Rs has been identified, ${ }^{19,23}$ the frequent close positioning of ER stacks and mitochondria in these cells has escaped attention. ER stacks are apposed to mitochondria at a frequency that indicates a specific binding between the two organelles, rather than the random effect of proximity within a limited space. Of 121 total profiles examined, 35\% are associations between 1-2 stacks and mitochondria, 25\% are stacks only and $40 \%$ are mitochondria only (Figures

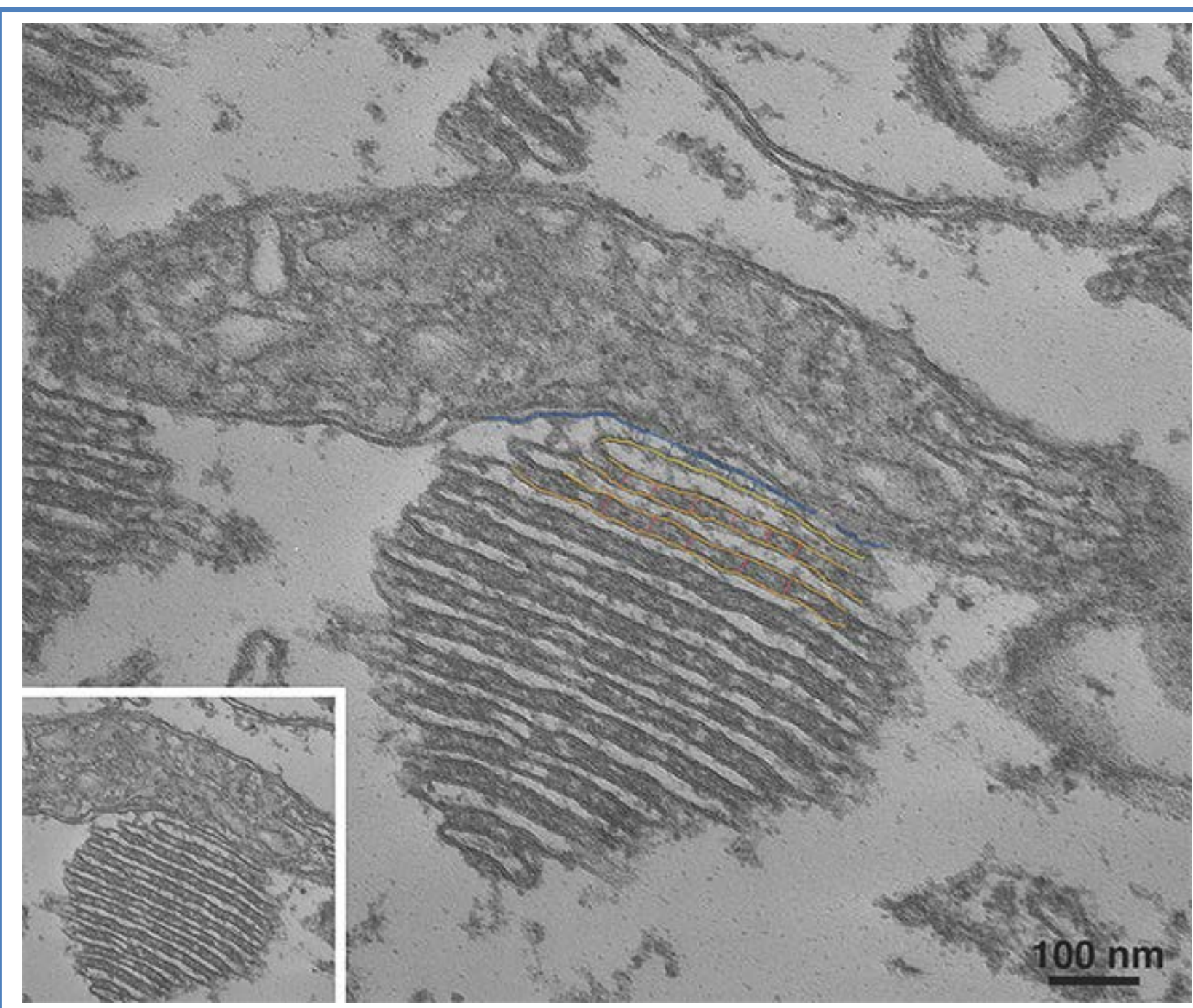

Fig 3. The average distance between proximal stack membrane (yellow) and mitochondrial membrane (blue) is 8.7 $\mathrm{nm}$. The distance between facing cisternae membranes in the stack (orange markers) is $14.8 \mathrm{~nm}$. The cytoplasmic domains of IP3 receptors do not fit into the narrower gap. 


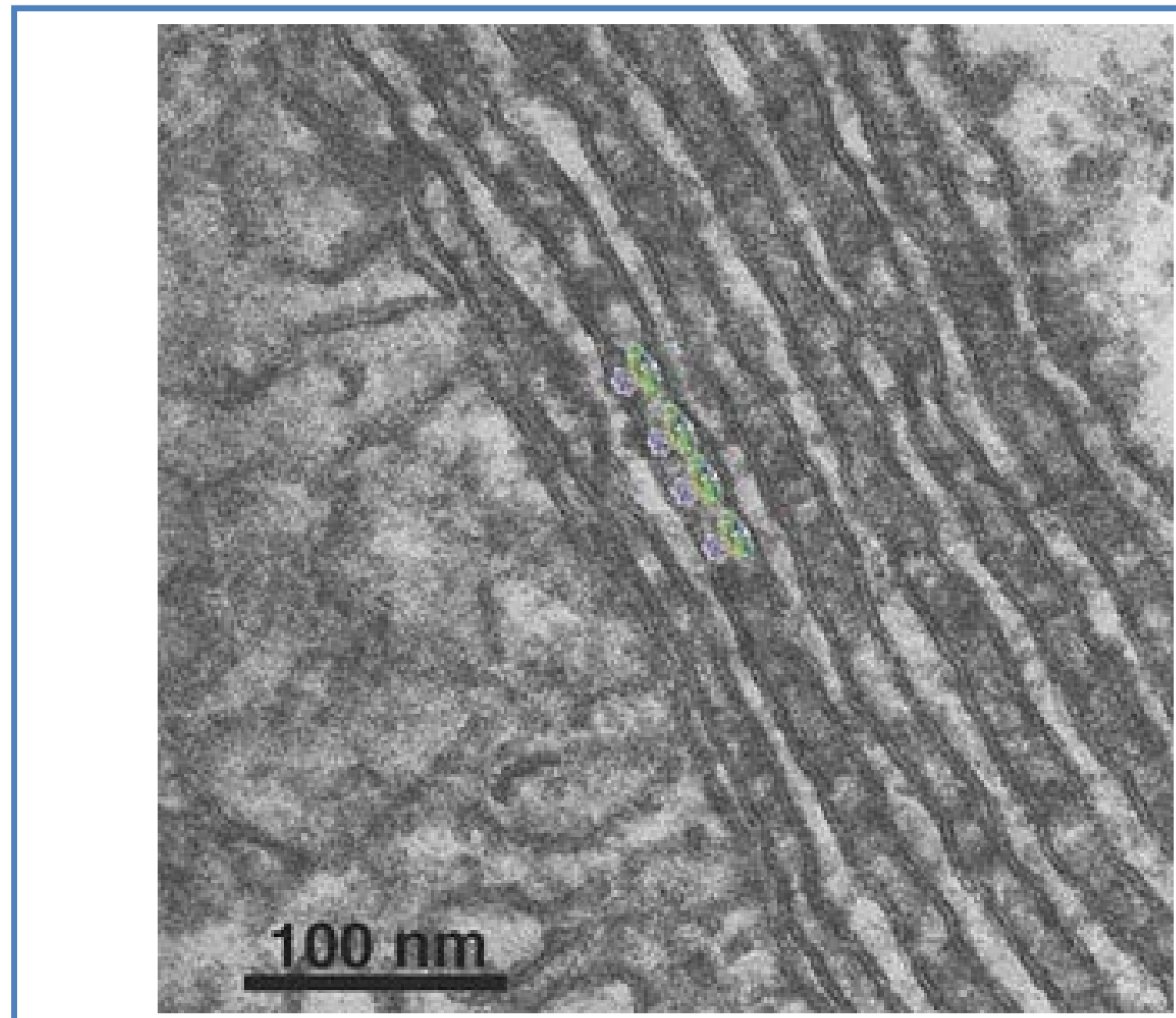

Fig 4. The scaled outlines of IP3Rs from5 are superimposed on a stack image. The channel domains overlap the membrane profile and the cytoplasmic domains are located in the inter membrane gap, accounting for the periodic densities.

The space between stack membranes accommodates the IPRs outlines, but the stack-to-mitochondrion gap is too narrow.

2 , 3). The frequency of associations is likely to be higher than these figures, because many of them are simply not included in the section thickness.

The stack-mitochondrion association is quite specific. In all cases a peripheral, smooth surface of the stack faces the mitochondrion and is closely apposed to it, while the rest of the stack, occupied by periodic densities between cisternae, earlier identified as IP3Rs, ${ }^{19}$ is on the opposite side. Coloring of the stacks' membranes and the lumen of each cisterna (Figure 2) is helpful in identifying the various components. The difference between the surfaces of ER cisternae closely opposed to mitochondria and those opposed to each other in the stacks is immediately apparent in a comparison between the stack-tomitochondrion distance (between yellow blue line) and inter-cisternae distance (yellow to yellow line, orange markers) in Figure 3. For accuracy, the distances were measured between the translucent central membrane layers and adjusted by subtracting the membrane thickness. The mean stack-mitochondrion intermembrane distance is 8.7+/-2.4 $\mathrm{nm} \quad(\mathrm{n}=22$ measurements), while the distance been cisternae membranes is $14.8+/-2.2 \mathrm{~nm}(\mathrm{n}=20)$.

Inter membrane distances in conventional electron micrographs are affected by artifacts during fixation and dehydration that result in shrinkages and in wrinkling of the membrane profiles. For that reason the measured values are not absolute. Despite these reservations, it is clear that the space between the cisternae occupied by evenly spaced densities is wider and most likely protected from shrinkage by the very presence of the IP3Rs The former space is wide enough to accommodate the cytoplasmic domains of a single IP3Rs layer with the channel domain contained within the membrane, as in Baker MR, Fan G, Serysheva I. (2017) ${ }^{5}$. By contrast, the stack-to-mitochondrion gap is too narrow to allow space for IP3Rs (Figure 4). 


\section{Discussion}

The association of Ip3R-rich ER stacks with mitochondria in cerebellar Purkinje cells is a striking example of mitochondria-associated ER membrane MAM. ${ }^{17}$ It is logical to assume that a tethering association exists between stacks and mitochondria such as illustrated for other ER/SR-mitochondria doublets. ${ }^{13,14,24}$ Within this association we can distinguish two components. The stacks' membrane facing the mitochondrion is separated from it by a narrow gap. These sites fall into in the category of "contacts", where the membrane proximity is of the type that permits direct communication between membrane components. ${ }^{13,14,25,26}$ Specific tethering of the SR stacks to the mitochondrion is suggested by the presence of small connecting structures and more significantly demonstrated by the frequency of stereospecific associations between mitochondria and SR. The intermembrane distance at the contact sites is too narrow to accommodate the cytoplasmic domains of IP3Rs, so the channels are excluded from the contact sites. The size of the ERmitochondria gap in other cases of close associations has not been systematically studied in the literature, but in general it seems to be narrow. The cytoplasmic domains of IP3Rs are located in the wide inter-lamellar spaces of mitochondria associated stacks and are thus at some, if small, distance from the mitochondrion. Under these conditions, uptake of $\mathrm{Ca}^{2+}$ by the mitochondrion takes advantage of the relatively large, localized and brief increase in cytoplasmic $\mathrm{Ca}^{2+}$ created by the release from ER. A small portion of the $\mathrm{Ca}^{2+}$ liberated into this microdomain site is rapidly and effectively taken up by the mitochondria located within a short distance from the release sites. ${ }^{27-30}$ Reuptake of $\mathrm{Ca}^{2+}$, by the $\mathrm{Ca}^{2+}$ ATPase located in the stacks, ${ }^{1,31}$ reduces the duration the $\mathrm{Ca}^{2+}$ spikes, thus providing the basis for short oscillatory responses that are followed by the mitochondria. ${ }^{9}$ The frequency of IP3R-rich stacks in Purkinje cells indicates requirement for a rapid, large $\mathrm{Ca}^{2+}$ release in response to IP3R activation (e.g., see Gomez LC, et al. 2020.) ${ }^{32}$ and the frequent stack-mito associations suggest that the mitochondria, despite their limited $\mathrm{Ca}^{2+}$ uptake, are designed to mitigate the release effect perhaps by reducing the $\mathrm{Ca}^{2+}$ transient duration. The relevance of location to the effect of mitochondria in $\mathrm{Ca}^{2+}$ distribution is beautifully illustrated by the example of exocrine cells in the pancreas. ${ }^{33}$

The concept of exchange of $\mathrm{Ca}^{2+}$ between ER/SR and mitochondria requiring proximity, but not an actual positioning of the $\mathrm{Ca}^{2+}$ release channels at the contact sites, was first emphasized, in the case of RyRs, for cardiac muscle, ${ }^{15}$ and is true for all varieties of skeletal muscles, e.g., see Franzini-Armstrong C, et al. (2011) ${ }^{18}$. In that respect cerebellar stacks and muscles dyads are analogous. It is not clear whether the IP3R exclusion from all mitochondrial contact sites detected in Purkinje cells applies to other extensive ER-mitochondria associations, such as those in liver cells. The relative scarcity of IP3Rs at these sites makes it basically impossible to reliably identify the IP3R channels in electron micrographs and the question remains open to further inquiry.

\section{List of acronyms}

E-C coupling - Excitation-Contraction coupling

IP3R - inositol 3 phosphate receptor

MAM - mitochondria associated membrane

RyR - ryanodine receptor

\section{Authors contributions}

RI analyzed data and wrote manuscript. CF-A performed electron microscopy and wrote manuscript. Both Authors approved the final typescript.

\section{Acknowledgments}

None

\section{Funding}

None

\section{Conflict of Interest}

The authors declare no conflicts of interests.

\section{Ethical Publication Statement}

We confirm that we have read the Journal's position on issues involved in ethical publication and affirm that this report is consistent with those guidelines.

\section{Corresponding Author}

Clara Franzini-Armstrong, Department of Cell and Developmental Biology, University of Pennsylvania, Philadelphia, USA 1-508 2747903.

ORCID iD: 0000-0001808 2094

E-mail: armstroc@pennmedicine.upenn.edu

\section{E-mail of co-author}

Ramesh Iyer: iyeerv1@chp.edu

ORCID iD: 0000-0001-8374-8468

\section{References}

1. Pozzan T, Rizzuto R, Volpe P, Meldolesi J. Molecular and cellular physiology of intracellular calcium stores. Physiol Rev. 1994 Jul;74(3):595636. doi: 10.1152/physrev.1994.74.3.595.

2. Mikoshiba K, Furuichi T, Miyawaki A. Structure and function of IP3 receptors. Semin Cell Biol. 1994 Aug;5(4):273-81. doi: 10.1006/scel.1994. 1033.

3. Berridge MJ. The endoplasmic reticulum: a multifunctional signaling organelle. Cell Calcium. 2002 Nov-Dec;32(5-6):235-49. doi: 10.1016/s0143416002001823.

4. Mikoshiba K. IP3 receptor/Ca2+ channel: from discovery to new signaling concepts. J Neurochem. 2007 Sep;102(5):1426-1446. doi: 10.1111/j.14714159.2007.04825.x.

5. Baker MR, Fan G, Serysheva II. Structure of IP3R channel: high-resolution insights from cryo-EM. 
Curr Opin Struct Biol. 2017 Oct;46:38-47. doi: 10.1016/j.sbi.2017.05.014. Epub 2017 Jun 12.

6. Franzini-Armstrong C, Protasi F. Ryanodine receptors of striated muscles: a complex channel capable of multiple interactions. Physiol Rev. 1997 Jul;77(3):699-729. doi: 10.1152/physrev.1997.77. 3.699 .

7. Rizzuto R, Bastianutto C, Brini M, Murgia M, Pozzan T. Mitochondrial Ca2+ homeostasis in intact cells. J Cell Biol. 1994 Sep;126(5):1183-94. doi: $10.1083 /$ jcb.126.5.1183.

8. Rizzuto R, Simpson AW, Brini M, Pozzan T. Rapid changes of mitochondrial $\mathrm{Ca} 2+$ revealed by specifically targeted recombinant aequorin. Nature. 1992 Jul 23;358(6384):325-7. doi: 10.1038/358325a0. Erratum in: Nature 1992 Dec 24-31;360(6406):768.

9. Hajnóczky G, Robb-Gaspers LD, Seitz MB, Thomas AP. Decoding of cytosolic calcium oscillations in the mitochondria. Cell. 1995 Aug 11;82(3):415-24. doi: 10.1016/0092-8674(95) 90430-1.

10. Rudolf R, Mongillo M, Magalhães PJ, Pozzan T. In vivo monitoring of $\mathrm{Ca}(2+)$ uptake into mitochondria of mouse skeletal muscle during contraction. J Cell Biol. 2004 Aug 16;166(4):52736. doi: $10.1083 /$ jcb.200403102.

11. Gillis JM. Inhibition of mitochondrial calcium uptake slows down relaxation in mitochondria-rich skeletal muscles. J Muscle Res Cell Motil. 1997 Aug;18(4):473-83. doi: 10.1023/a:1018603032590.

12. izzuto $R$, Brini $M$, Murgia $M$, Pozzan $T$. Microdomains with high $\mathrm{Ca} 2+$ close to IP3sensitive channels that are sensed by neighboring mitochondria. Science. 1993 Oct 29;262(5134):744-7. doi: 10.1126/science. 8235595.

13. Csordás G, Weaver D, Hajnóczky G. Endoplasmic Reticulum-Mitochondrial Contactology: Structure and Signaling Functions. Trends Cell Biol. 2018 Jul;28(7):523-540. doi: 10.1016/j.tcb.2018.02.009. Epub 2018 Mar 24.

14. Csordás G, Renken C, Várnai P, Walter L, Weaver D, Buttle KF, Balla T, Mannella CA, Hajnóczky G. Structural and functional features and significance of the physical linkage between ER and mitochondria. J Cell Biol. 2006 Sep 25;174(7):91521. doi: 10.1083/jcb.200604016. Epub 2006 Sep 18.

15. Sharma VK, Ramesh V, Franzini-Armstrong C, Sheu SS. Transport of $\mathrm{Ca} 2+$ from sarcoplasmic reticulum to mitochondria in rat ventricular myocytes. J Bioenerg Biomembr. 2000 Feb;32(1):97-104. doi: 10.1023/a:1005520714221.

16. Boncompagni S, Pozzer D, Viscomi C, Ferreiro A, Zito E. Physical and Functional Cross Talk Between Endo-Sarcoplasmic Reticulum and Mitochondria in Skeletal Muscle. Antioxid Redox
Signal. 2020 Apr 20;32(12):873-883. doi: 10.1089/ars.2019.7934. Epub 2019 Dec 11.

17. Hayashi T, Rizzuto R, Hajnoczky G, Su TP. MAM: more than just a housekeeper. Trends Cell Biol. 2009 Feb;19(2):81-8. doi: 10.1016/j.tcb.2008. 12.002. Epub 2009 Jan 12.

18. Franzini-Armstrong C, Boncompagni S. The evolution of the mitochondria-to-calcium release units relationship in vertebrate skeletal muscles. J Biomed Biotechnol. 2011;2011:830573. doi: 10.1155/2011/830573. Epub 2011 Oct 13.

19. Katayama E, Funahashi H, Michikawa T, Shiraishi $\mathrm{T}$, Ikemoto $\mathrm{T}$, Iino $M$, Mikoshiba $K$. Native structure and arrangement of inositol-1,4,5trisphosphate receptor molecules in bovine cerebellar Purkinje cells as studied by quick-freeze deep-etch electron microscopy. EMBO J. 1996 Sep 16;15(18):4844-51. Erratum in: EMBO J 1996 Dec 16;15(24):7188.

20. Paolini C, Protasi F, Franzini-Armstrong C. The relative position of RyR feet and DHPR tetrads in skeletal muscle. J Mol Biol. 2004 Sep 3;342(1):14553. doi: 10.1016/j.jmb.2004.07.035.

21. Khodakhah K, Armstrong CM. Induction of longterm depression and rebound potentiation by inositol trisphosphate in cerebellar Purkinje neurons. Proc Natl Acad Sci U S A. 1997 Dec 9;94(25):14009-14. doi: 10.1073/pnas.94.25. 14009 .

22. Lavorato M, Franzini-Armstrong C. Practical solutions to frequent problems encountered in thin section electron microscopy. Microscopy Today. 2017; May: 1-5.

23. Satoh T, Ross CA, Villa A, Supattapone S, Pozzan T, Snyder SH, Meldolesi J. The inositol 1,4,5,trisphosphate receptor in cerebellar Purkinje cells: quantitative immunogold labeling reveals concentration in an ER subcompartment. J Cell Biol. 1990 Aug;111(2):615-24. doi: 10.1083/jcb.111.2.615.

24. Boncompagni S, Rossi AE, Micaroni M, Beznoussenko GV, Polishchuk RS, Dirksen RT, Protasi F. Mitochondria are linked to calcium stores in striated muscle by developmentally regulated tethering structures. Mol Biol Cell. 2009 Feb;20(3):1058-67. doi: 10.1091/mbc.e08-070783. Epub 2008 Nov 26.

25. Pinton P, Giorgi C, Siviero R, Zecchini E, Rizzuto R. Calcium and apoptosis: ER-mitochondria Ca2+ transfer in the control of apoptosis. Oncogene. 2008 Oct 27;27(50):6407-18. doi: 10.1038/onc.2008.308.

26. Scorrano L, De Matteis MA, Emr S, Giordano F, Hajnóczky G, Kornmann B, Lackner LL, Levine TP, Pellegrini L, Reinisch K, Rizzuto R, Simmen T, Stenmark H, Ungermann C, Schuldiner M. Coming together to define membrane contact sites. Nat 
Commun. 2019 Mar 20;10(1):1287. doi: 10.1038/s41467-019-09253-3.

27. Rizzuto R, Pinton P, Carrington W, Fay FS, Fogarty KE, Lifshitz LM, Tuft RA, Pozzan T. Close contacts with the endoplasmic reticulum as determinants of mitochondrial $\mathrm{Ca} 2+$ responses. Science. 1998 Jun 12;280(5370):1763-6. doi: 10.1126/science.280.5370.1763.

28. Rizzuto R, Pozzan T. Microdomains of intracellular Ca2+: molecular determinants and functional consequences. Physiol Rev. 2006 Jan;86(1):369408. doi: 10.1152/physrev.00004.2005.

29. Rizzuto R, Brini M, Murgia M, Pozzan T. Microdomains with high $\mathrm{Ca} 2+$ close to IP3sensitive channels that are sensed by neighboring mitochondria. Science. 1993 Oct 29;262(5134):744-7. doi: 10.1126/science. 8235595.

30. Taylor CW, Tovey SC, Rossi AM, Lopez Sanjurjo CI, Prole DL, Rahman T. Structural organization of signalling to and from IP3 receptors. Biochem Soc Trans. 2014 Feb;42(1):63-70. doi: 10.1042/BST20130205.
31. Fierro L, DiPolo R, Llano I. Intracellular calcium clearance in Purkinje cell somata from rat cerebellar slices. J Physiol. 1998 Jul 15;510 ( Pt 2)(Pt 2):499512. doi: 10.1111/j.1469-7793.1998.499bk.x.

32. Gomez LC, Kawaguchi SY, Collin T, Jalil A, Gomez MDP, Nasi E, Marty A, Llano I. Influence of spatially segregated IP3-producing pathways on spike generation and transmitter release in Purkinje cell axons. Proc Natl Acad Sci U S A. 2020 May 19;117(20):11097-11108. doi: 10.1073/pnas.2000 148117. Epub 2020 May 1. Erratum in: Proc Natl Acad Sci U S A. 2020 Jun 9;117(23):13176.

33. Tinel H, Cancela JM, Mogami H, Gerasimenko JV, Gerasimenko OV, Tepikin AV, Petersen $\mathrm{OH}$. Active mitochondria surrounding the pancreatic acinar granule region prevent spreading of inositol trisphosphate-evoked local cytosolic $\mathrm{Ca}(2+)$ signals. EMBO J. 1999 Sep 15;18(18):4999-5008. doi: 10.1093/emboj/18.18.4999.

Submission: June 232021

Revision received: August 6, 2021 Accepted for publication: August 6, 2021 